\title{
How Error Prevention and Organizational Silence Influences Managers' Self-Perception - A Repertory Grid Study
}

http://doi.org/10.21272/bel.5(1).31-44.2021

Laura Kussin, ORCID: https://orcid.org/0000-0002-3190-397X

M. Sc., Faculty of Business, Language and Culture, Flensburg, Germany

Henning Bundtzen, ORCID: https://orcid.org/0000-0002-0098-8886

PhD Candidate, Organizational Developer, Faculty of Economic Science, Szent István University Budapest, Hungary

\begin{abstract}
The topic of self-perception within management has become a subject catching more and more attention. The necessity for leaders' self-awareness when aiming at high employee satisfaction and productivity still bears a lot of research potential. Developing self-awareness and efficacy are paths that do not have an end or a quota to reach. It is a rather mindset like a tank that can always be filled up more. Leaders' self-awareness is crucial to improve their abilities and much more inaccurate self-perception can become harmful for an organisations' performance. Surprisingly, the influence of managers' self-perception on leadership behaviour and leadership effectiveness has only been studied little in contemporary literature. The main purpose of this article is to identify organizational factors that influence leader's self-perception and how an organization can develop this characteristic of their managers. Therefore, this paper aims at identifying corporate cultural causes for managers' distorted self-perception. This task leads evidently to the topic of organizational silence, which is understood as the absence of upward-directed feedback of employees' input of ideas. Consequently, a corporate culture inherited by organizational silence impacts a manager's self-perception.

Additionally, the contextual literature research on self-perception guided to the subject of error management. It becomes evident that error management functions as a link between organizational silence and managers' overestimation. Summarizing the article studies the interlinkages of these three research areas and combined them with a new research and hypothesis model tested on a repertory grid data set consisting of 782 personal constructs of a specific corporate culture. Individual construct psychology was chosen as an investigative methodology to ensure unbiased qualitative results. This psychologically grounded methodology is proven to make socially desirable results unlikely due to the intuitive interview structure. The results of this research give practitioners advice for developing corporate culture and self-perception and efficacy of people in leadership positions.
\end{abstract}

Keywords: Organizational Silence, Error Management, Self-perception in Leadership, Feedback Culture, Repertory Grid Analysis, Personal Construct Psychology.

JEL Classification: M14, M5, J50, M54.

Cite as: Kussin, L., Bundtzen, H. (2021). How Error Prevention and Organizational Silence Influences Managers' Self-Perception - A Repertory Grid Study. Business Ethics and Leadership, 5(1), 31-44. http://doi.org/10.21272/bel.5(1).31-44.2021.

Received: 01 January $2021 \quad$ Accepted: 09 March $2021 \quad$ Published: 30 March 2021

Copyright: (C) 2021 by the author. Licensee Sumy State University, Ukraine. This article is an open access article distributed under the terms and conditions of the Creative Commons Attribution (CC BY) license (https://creativecommons.org/licenses/by/4.0/).

\section{Introduction}

Looking at social media, a person's self-awareness and self-perception become central topics in our contemporary working environment. However, in the management literature, self-awareness still seems to be a topic missing appropriate research (Bruce et al., 2003; Flynn et al., 2016; Silvia and Duval, 2001). Thus, the importance and influence of managers' self-perception and self-awareness make up a significant part of this paper. When studying this topic, evidently two additional subjects are named in the same context. Firstly, organizational silence (OS), defined as employees are not giving upward-directed feedback to their managers (Frederick et al., 2019; Morrison and Milliken, 2000; Pinder and Harlos, 2001). Besides, ideas are not brought 
forward, which in return influences the firm's performance and development. In an economic environment that is increasingly volatile, complex, and uncertain employee commitment and engagement become increasingly important as managers alone cannot have a fast answer to each situation. The pandemic year 2020 has proven this arrestingly as drastic economic and governmental changes were the consequence to which each organization had to react. In such a business environment it is unlikely that leaders do not make mistakes with their decision which leads to the third topic of this research. Error management deals with the treatment of errors that arise without purpose. Missing knowledge, uncertain situations or ambiguous customer preferences can be other factors leading to wrong decisions (Frese and Keith, 2015). It means that individual mistakes cannot be reduced to zero. Humans commit two to four mistakes per hour on average, which stresses the requirement for error-handling techniques instead of aiming at preventing human errors entirely (Prümper et al., 2007). This paper aims to identify how these three topics influence and link to each other to advance research in this area. In a literature review, recent scientific evidence was gathered and brought into a research model. The hypothesis advocated in that model was tested on a data set assembled in 61 qualitative interviews based on personal construct psychology. This approach creates qualitative and quantitative data on the leader-memberexchange (LMX) that visualize the relations mentioned above. Cluster analysis generated results that show a strong deviation from the leaders' self-perception compared to the entire leadership culture. It indicates a case of distorted self-evaluation by leaders and the cultural climate that leads to such a scenario.

\section{Literature Review}

Self-Perception in Leadership. It is necessary to point out that humans generally tend to perceive themselves positively and overestimate their competencies (Atwater et al., 1998; Silvia and Duval, 2001). Also, positive self-perception is a sign of mental health (Whitton et al., 2008). However, managers' overestimation can become a real danger to the company they work with (Guenther and Alicke, 2010).

The concept from Atwater and Yammarino (1992) is chosen for this paper to evaluate accurate or inaccurate self-perception. Atwater and Yammarino (1992) distinguish three types when describing self-awareness: overestimators, in-agreement, and under-estimators. Over-estimators consider themselves distinctively higher than their social environment does. As the discrepancy between self-and other evaluation points out, overestimators rate the lowest in self-awareness within this concept. Since over-estimators are convinced about the correctness of their habits and behaviour people within this category mostly do not identify any need for personal change or improvement (Ashford and Susan, 1989). Tekleab et al. (2008) stress that managers overestimating themselves rate low in leader-effectiveness, pointing out the danger overestimation in leadership holds. Additionally, in the case of an unrealistic positive self-view, Sputtek (2012) emphasizes managers' tendency to show little interest in subordinates' feedback, which can hurt employees' job satisfaction. Second, in-agreement refers to people who perceive themselves as similar to how others perceive them; thus, self-and other-evaluation match each other (Atwater and Yammarino, 1992).

Consequently, people within this category rate highest in self-awareness (Atwater and Yammarino, 1992) and rank highest in leader-effectiveness (Tekleab et al., 2008). Due to the acceptance of others' judgment and high locus of control, managers within this category tend to accept subordinates' feedback (Sputtek, 2012) and are open to change in their habits and behaviour (Atwater and Yammarino, 1992). The last category of underestimators includes people who rate themselves worse than others rate them. Hence, leaders underestimating themself rank better in leader-effectiveness than over-estimators but worse than leaders clustered in the category in-agreement (Atwater et al., 1998). This effect is assumed to be caused by the person's little belief in self-efficiency combined with low self-confidence leading to no incentives to improve their behaviour (Atwater et al., 1998; Tekleab et al., 2008). All in all, over-estimation can become a threat to the organisational culture and a company's performance. Additionally, discrepancies in leaders' self and other evaluation are associated with a hostile and defensive organisational climate, especially when leader over-estimate themselves (Aarons et al., 2015).

Atwater et al. (1995) emphasize the importance of upward feedback to raise self-awareness. Leaders, receiving upward-feedback, tend to adapt their self-ratings and, thereby, decrease the discrepancy between self and otherevaluation and increase their self-awareness (Atwater et al., 2000). In their study, Walker and Smither (1999) showed that leaders who discussed their received feedback with their subordinates increased their leadership performance even more. Hence, upward feedback is one major instrument to improve managers' selfawareness. Beyond that, London and Smither (2002) stress the difference between mastery and performance orientation. A person holding a mastery orientation is understood as interested in learning and becoming an expert (Dweck, 1986; Ramani et al., 2018). Due to this orientation, negative feedback is viewed as the possibility to learn new things and improve the course of action (Ramani et al., 2018). Controversially, a person 
holding a performance orientation wants to reach the best performance possible and keeps comparing his or her work with others (London and Smither, 2002). In this context, negative feedback is mainly a threat to that person and can thus result in the tendency to avoid feedback (Gong et al., 2017).

Organizational Silence. As this paper addresses the topic of organizational silence, we surely want to introduce this phenomenon shortly. Organizational silence, institutionalized and collective employee silence (Frederick, 2019), describes the phenomenon when employees within an organization or company willingly withhold their critics or ideas about given topics (Frederick, 2019; Morrison and Milliken, 2000; Pinder and Harlos, 2001). As a company's human resource is one important informational source, the danger organizational silences seem obvious (Morrison et al., 2015). Sutcliffe (2011) even describes organisational communication as a resource holding the possibility to create a competitive advantage.

Frederick (2019) and Van Dyne et al. (2003) distinguished employee silence into three different types: passive, defensive, and pro-social silence. The first one occurs mostly due to perceived negative leadership behaviour as a form of reprisal or resignation (Frederick, 2019). Defensive silence describes the phenomenon that people mostly try to avoid delivering a lousy message for self-protection (Van Dyne et al., 2003). Van Dyne et al. (2003) define defensive silence as a proactive and self-oriented form of self-protection, which is consequently motivated by fear. The last type, pro-social silence, is other-oriented (Van Dyne et al., 2003) and aims at protecting other colleagues or the organization by withholding inappropriate and harmful information (Frederick, 2019). Additional to the concept of employee silence, we want to stress the need to add parts of Van Dyne et al. (2003) concept of employee voice. Commonly, employee voice is understood as advocacy participation, the proactive choice to bring in ideas and information constructively, which can be helpful and beneficial for the organization (Gao et al., 2011; Tangirala and Ramanujam, 2012; Van Dyne et al., 2003; Zhou and Georg, 2001). Van Dyne et al. (2003) name this type of behaviour pro-social voice. However, they also introduce the defensive and passive voice, which describes employees speaking up but simultaneously withholding their true beliefs. Defensive voice includes employees' behavior blaming others for shifting attention to protect the self (Morrison and Milliken, 2000). Like defensive silence, defensive voice is also motivated by fear and aims to avoid negative consequences (Arkin and Shepperd, 1989). Even though voice can be viewed as the contrary to silence, we include defensive and passive voice in our understanding of organizational silence.

The two main reasons why organizational silence appears within an organization were introduced by Morrison and Milliken (2000). Based on Ghoshal and Moran (1996), they point out that (1) many managers hold negative implicit beliefs about their employees and that (2) managers often fear negative feedback. Moreover, Morrison and Milliken (2000) point out that such ideas have a self-fulfilling impact and create a climate hindering open communication. Furthermore, these two reasons for organizational silence are often accompanied by the belief that unity and homogeneity within organizations are worthwhile (Burell and Morgan, 1979). Kane-Urrabazo (2006) emphasizes the crucial role that managers hold when shaping the organizational culture and, thus, the psychological environment of an organization (Schein and Schein, 2010). As one can see, reasons for the existence of organizational silence must, to a large extent, be looked for within the management.

Error Management. Closely linked to the subject of organizational silence is the inner organizational treatment of errors. Consequently, we studied the literature addressing this area in business research. Also, error management seems to be a topic missing in-depth studies. When we discuss errors or mistakes in a business context, we must distinguish them from the active violation. First, the active violation is an intentional act to harm someone or something purposefully (Hofmann and Frese, 2011). In contrast, a mistake happens without intention and due to missing knowledge (Frese and Keith, 2015). It implies that human errors cannot be reduced to zero; instead, humans commit two to four mistakes per hour on average (Prümper et al., 2007). This fact emphasizes the need for strategies handling errors instead of reducing human errors to zero.

However, in the business context, errors are mostly understood as something unpleasant that needs to be punished and should not happen again (Keith and Frese, 2008). Frese and Keith (2015) introduce two strategies for handling errors in a business context: (1) Error Prevention and (2) Error Management. In error prevention, mistakes are understood as a dangerous obstacle and a symbol of lacking intelligence (Frese and Keith, 2015). Hence, people committing errors might be evaluated upon them. Consequently, employees tend to hide and willingly overlook their mistakes caused by fear of the following consequences. (Frese and Keith, 2015). Also, in an environment with such an error mindset shaped by fear and distrust people tend to blame others and use finger-pointing as a strategy to protect themselves (Gao et al., 2011). Since people tend to hide their errors and do not communicate them, errors within this strategy are mostly detected over error-cascades (Frese and Keith, 2015). At this point, damage control can become quite costly for an organization or might no longer be possible 
(Fischer et al., 2018). Thus, this strategy holds the possibility to create even more errors and hinders the evolvement of innovation (Frese and Keith, 2015).

Contrary, in error management, mistakes are understood as feedback or an opportunity to learn from (Frese and Keith, 2015). This mindset makes people feel safe in admitting to their mistakes and revealing them to their colleagues (Frese and Keith, 2015). Consequently, processes for damage control can be activated much earlier than in error prevention (Keith and Frese, 2005). Open communication and team learning are an essential part of the error management strategy. (Frese and Keith, 2015). Since innovation processes depend on how errors are treated, whether an organisation supports experimentations or instead blames someone for making mistakes (Fischer et al., 2018), error management offers room for innovation. Also, communication about mistakes accelerates damage control and spreads information and knowledge about a mistake. Hence, colleagues can learn from errors conducted by other employees and prevent repetition (Frese and Keith, 2015).

Hypothesis Development. From our literature review, we derive the following four hypotheses the combine and interlink the topics self-perception in leadership, organizational silence, and error management. First, we assume that in case of an error prevention strategy, employees already aim at making or at least pretending to make few or no mistakes. In case this strategy is combined with a culture of performance orientation, employees will tend to stay silent to protect themselves from critical feedback.

\section{$H_{1}$ : Error Prevention in combination with performance orientation support organizational silence.}

Organizational silence, in return, is reflected in the absence of upward feedback from employees to the leaders of the organization. When employees stay silent and do not give critical upward feedback towards their supervisors, managers have no incentive to reflect their leadership behaviour critically, hence, assume it is correct. Additionally, since an error prevention culture creates fear and stress for a person committing a mistake, this culture will not appreciate it but rather devaluate it. In case this corporate culture is combined with organizational silence, managers or supervisors do not receive critical feedback and have no incentive to change or adapt their behaviour. Furthermore, in a corporate error prevention culture, people in top positions believe in making fewer mistakes than others or are especially good at hiding or blaming others for them. Accordingly, managers or leaders in such a corporate environment tend to overestimate themselves.

$\mathrm{H}_{2}: \quad$ Absence of feedback in combination with error prevention leads to a discrepancy between self- and other evaluation.

Organizational silence transmitted via overestimation and missing reflection of leadership in combination with the absence of accountability and responsibility will result in a devaluated corporate culture. Consequently, leaders' overestimation, organizational silence and error prevention strategy reduces employee's willingness to take on responsibility. In combination, these factors lead to a devaluation of the underlying corporate culture.

$H_{3}$ : Managers' overestimation is supported by a culture in which responsibility is not taken on by employees resulting in a devaluation of the corporate culture.

The postulated relationships between performance orientation, error prevention culture and self-perception in leadership, posited in the four hypotheses above, can graphically be displayed in the following research and hypothesis model:

\section{$\begin{array}{lll}\text { Antecedents } & \text { Behaviour } & \text { Outcome }\end{array}$}

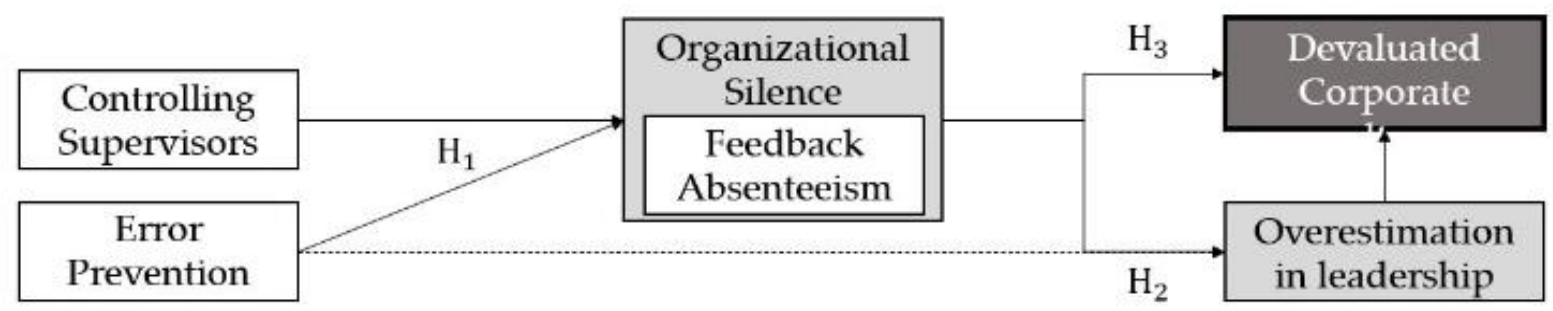

Figure 1. Research and Hypothesis Model

Source: Compiled by the authors

In the following chapter, we describe how this model is tested using Kelly's theory of personal construct from psychology to investigate corporate culture with repertory grid structured interviews. 


\section{Methodology and Research Methods}

A systematic review has been conducted summarizing the topics of self-perception in leadership, organizational silence, and error management. The theoretical findings' hypothesis was withdrawn and tested qualitatively and quantitatively against a comprehensive data basis. The data basis consists of 61 repertory grid structured interviews carried out within an organization eliciting 782 personal constructs. This qualitative research employs an inductive approach to study the self-perception of leaders in a work environment. A reconciliation of the latest scientific literature with Kelly's (1955) personal construct psychology (PCP) in a grid study supplied a theoretical methodology and background to create a comprehensive data set that allows an initial verification of the research and hypothesis model created. In his hypothesis, Kelly (1955) suggested that people and scientists constantly try to make sense of their universe and their place in this world. (Cassell et al., 2000). It is done by putting experiences and things in relation to each other in different contexts (Fromm, 2004). The theory is extended within the framework of this analysis to an organisation surrounding an entity. It suggests that an initially philosophical hypothesis of how persons subjectively make sense of their environment is used to determine how workers judge the company for which they work for leadership self-perception. Besides, we hope to find evidence of organizational silence and a proposition on the organizations approach to error management.

Hence it is a method that investigates the subjective and personal worlds of workers within an organization. PCP argues that people create individual constructions or hypotheses of themselves and their organisation, depending on the sum of their interactions (Fransella et al., 2004). Why did we choose this special technique? An impartial qualitative and quantitative approach repertory grid supports whether the three topics investigated are represented (Robertson, 2004). The methodology is not a psychometric test but rather a structured interview technique based on PCP (Fromm, 2004) that externalize the deep thoughts of a workforce in an intuitive way. The theory is based on similarities and dissimilarities between organizational elements with which participants distinguish these elements. Their wording to differentiate these elements are recorded in a data matrix (Scheer and Catina, 1993). The results represent the subjective reality of the interviewed person in an idiographic way (Bourne and Jankowicz, 2018).

The research object under review is a wholesale business that employs approx. 500 staff. 21 members of the team are in managing positions. Beginning of the year 2019 the interviews were conducted. A software named rep: grid was utilized for the collection and analysis of the interviews. The tool allows the researcher to choose between several interview setting. For this research, the comparison method triad oppositional was chosen. This means that the interviewees were presented three different elements to elicit their constructs. The evaluation method was conducted in a tetrapolar field. The web based tool is able to generate the results after finishing the interview to enable consensual validity of the elicited constructs (Lohaus, 1983).

The main purpose of this study is to examine whether the use of Kelly's theory of personal constructs as a research paradigm will validate our postulated hypothesis. Therefore, organized repertory grid interviews were performed in all company branches, including each of the 21 managers and 40 staff. Every face-to-face interview assisted by the software lasted 120 minutes and produced an average of 13 individual constructs per interview. The staff were chosen proportionally to the department size. The applied repertory grid methodology asks the interviewee to create a construct about their association with the components presented in a qualitative matter in their wording (Goffin, 2003). It is because their understanding of the entity around them is built through their frameworks or metrics that embody the components that define the organization by measuring and assessing them (Kelly, 2002). The determination of elements must obey particular simple guidelines to safeguard a universal coverage of the study subjects. The main criteria for the selection of items are that they need to be homogeneous. It means that they are from the same group, that they should be descriptive of the subject investigated and that the interviewee should be unequivocal (Easterby-Smith et al., 1996). Besides, it is advised to deploy heterogeneous components that denote a consequential reflection of the studied topic (Wright and Lam, 2002). The following 27 components describe the organization in this study and are meant to establish structures about the subjects studied: 
Table 1. Elements Employed to Investigate Corporate Culture

\begin{tabular}{|c|c|c|}
\hline \multicolumn{2}{|c|}{ All elements } \\
\hline The organization \& market & Leadership \& Motivation & Quality and internal processes \\
\hline The company as it used to be & Myself today & HR \\
\hline The company today & My direct manager & Sales Department \\
\hline The company in 2.5 years & The company without leadership & IT \\
\hline The ideal company & Ideal leadership & Marketing \\
\hline A negative company & Leadership culture & Employee culture \\
\hline The companies brand & Myself as a manager & Quality principle \\
\hline The market in the future & CEO 1 & An efficient process \\
\hline An unpleasant competitor & CEO 2 & A highly motivated person \\
\hline A meaningful company & &
\end{tabular}

Source: Compiled by the authors

The 27 components are divided into three major subjects. Error management is not integrated explicitly in the set of components. Purposely this description was excluded as too apparent elements would explicitly generate ideas for related behaviours about failures that may have resulted in false outcomes. Nevertheless, in conjunction with the element Quality principle, Kelly's (1991) inductive personal construct theory encouraged the interviewees to word error management-related constructs while preventing the inclusion of thoughts that they do not practice in the sense of judging the organization. Elements such as the Quality principle or An efficient process encourage innovative ideas in this elicitation process to preferably evoke a set of qualitatively distinguishable metaphors that characterize organizational culture.

The elements stated above were kept constant while conducting this study which permits reconciliation of several personal realities into the direct quantitative relationship (Hauser et al., 2011). It becomes evident that in particular, the components Myself today, My direct Manager, Leadership culture and Employee culture were selected to elicit concepts from our field of investigation. The intuitive methodology utilized still enabled the interviewees to state self-perception, OS and error-related constructs. Riemann (1991) and Lohaus (1983) demonstrated that the similarity testing of elements shows temporal stability and is in accordance with structures generated through alternative research methods. They concluded that there are no deficiencies regarding reliability and validity by the repertory grid technique as a research approach (Feixas et al., 2002). It has the same value as traditional methodologies; hence traditional quality criteria of assurance can be used for this type of interview technique (Fromm, 2004).

The protocol of organized interviews with the repertory grid can be broken into three stages: 1 . The approach allows the interviewees to assess a triad of three different components from the list of 27 to construct their evaluation criteria. The participants were given three elements and questioned, "Which two elements are similar and distinct to the third element?" During their job, the elements accompany the individuals and are connected to business philosophy and leadership. Consequently, these objects are included in people's everyday thoughts and interactions (Senior and Swailes, 2004). In phase two, the interviewees state a contrary to their originally elicited construct followed by the third phase in which they rate all 27 components by their assessment criteria. That way, they are only presented with elements that accompany them instead of posing precise questions to the interviewees as an employee of the examined company defines its environment through similarities and discrepancies of structures (Kelly, 1991). For the third phase, a tetrapolar field is utilized for evaluation. It makes for a diverse selection of potential assessments (Senior and Swailes, 2004). Until no more constructs were produced, this procedure was replicated. The following elements and coordinates should be positioned in the direct sense of the subjects examined within the collection mentioned above of elements since they theoretically contribute to thoughts that apply to an organization's cultural facts.

Table 2. Main Elements Linked to Self-perception, OS and Error Management

\begin{tabular}{|l|c|c|c|}
\hline \multicolumn{1}{|c|}{ Element } & Spread & Variance & Fulfilment Degree \\
\hline A negative company & 8.85 & 0.0098 & 1.000 \\
\hline Employee culture & 26.46 & 0.0188 & 0.216 \\
\hline Leadership culture & 23.65 & 0.0282 & -0.005 \\
\hline Myself as a manager & 31.72 & 0.0039 & -0.307 \\
\hline My direct manager & 25.81 & 0.031 & -0.553 \\
\hline Myself today & 20.01 & 0.0282 & -0.773 \\
\hline Ideal leadership & 15.38 & 0.0365 & -0.936 \\
\hline The ideal company & 9.2 & 0.0119 & -1.000 \\
\hline
\end{tabular}

Source: Compiled by the authors 
In particular, the components of Myself as a manager and Leadership culture can evoke constructs that differentiate a manager's self-perception and the perception by third persons visible. The component $A$ quality principle was picked as an element to facilitate the creation of error-related topics. Based on the sum of their perceptions, the constructions consist of the interviewed individuals' natural wording. Consequently, participants do not respond to concerns and considerations that they did not care about until doing so. As OS and error prevention is closely related to leadership, several elements were chosen which provoke experiences and thoughts about this topic.

A dedicated software that applies Generalized Procrustes Analysis (GPA) evaluates the individual coordinates for all components and assessment criteria. Three-dimensional data matrices can be estimated that way and visualized by GPA (Mak et al., 2013). That way, the study demonstrates how the obtained structures are clustered and how they are related to one another. (Gower, 1975; Grice and Assad, 2009). The program calculates the spaces between the classified components and generates numerical measures to explain the probability of structures occurring coincidentally in the same metric location (Tomic et al., 2015). In line with their unique coordinates, the system clusters them automatically. The elicitation of the elements above does not cause any derived constructs to be expected, but the context dictates that the subject-related constructs are formed (Fransella, 2004). The elicited matrix analysis relies on the recognition of equally meaningful construction clusters (Hauser et al., 2011). The relationship between the location of elements in combination with associated constructs allows insights into the interviewees' subjective worlds. The GPA was limited to three dimensions to ensure practicability and descriptive qualitative analysis because this way, the results can be presented in three-dimensional plots.

An interpretation of the results requires a common understanding of the spatial representation demonstrated in the 3D graphics of this study. The distances between clusters of constructs and elements and their allocation in the three-dimensional space are quantitative figures that allow their interplay a qualitative analysis of the repertory grid. In case the coordinates of constructs and elements represent a small, extraordinary distance, this means they rate similarly. To receive two factors that are located on the same coordinates, they must be evaluated identically on each elicited construct within the tetrapolar field. It would result in a distance of zero between the two elements. The data is analysed by the spatial correlation of features and the centric position of created clusters. Parts and the centric point of a cluster have a distinct set of coordinates that allow to measure the distances as a percentage of 100. As an example, "The ideal company" and "Ideal Leadership" have a distance of 0.9 , reflecting a degree of correlation of $99.1 \%$, which is somehow expected. The opposite is the case if two elements are rated contrary on all elicited constructs, they would represent a relative space distance of $100 \%$. The distance between A negative company and The ideal company is 74.5, a correlation of $25.5 \%$. For testing our hypothesis, we define the following corridors:

Table 3. Defined Corridors for the Degree of Association

\begin{tabular}{|c|c|}
\hline Type & Degree of association \\
\hline Actual association & $75-100 \%$ \\
\hline Indifferent & $50-75 \%$ \\
\hline Reverse association & $25-50 \%$ \\
\hline
\end{tabular}

Source: Compiled by the authors

Orientation is given in this three-dimension space by the two elements, A negative company and The ideal company, as these two elements reflect the positive and negative pole for our research. The relative distances (of a maximum of 100) to these poles indicate how positive or negative a topic is seen. Low distances between constructs and elements show a similarity in their rating and meaning. This way, the particular alignment of elements in construct clusters enables the researcher to interpret the repertory grid results intuitively.

The data matrix produced by the GPA allocates to each construct and element a unique set of coordinates. The software rep: grid can be utilized to create a certain set of clusters depending on the closeness of constructs whilst including all constructs. This preview cluster set must be reviewed as it is a pure mathematical determination. For this research, the functionality was used to create the first set of clusters as a basis. In a second step, all constructs were reviewed in a qualitative content analysis regarding their coherence. In a final qualitative approach, all constructs were semantically assessed and allocated to one initial or a new cluster. The semantical review resulted in 34 clusters for which rep:grip allocated the centric position of each cluster by again applying GPA. It allows to evaluate which organizational element the employees and managers associate with a specific element. 


\section{Results}

The personal constructs elicited in this research were semantically summarized into 34 clusters of which each contained between 13 and 34 constructs. These clusters in turn can be summed up into 5 main topics. 71 personal constructs are classified as unassigned as they did not fit into the below listed scheme.

Table 4. Construct Clusters and Their Degree of Association with Elements

\begin{tabular}{|c|c|c|c|c|c|c|c|c|}
\hline & & \multicolumn{2}{|c|}{ Constructs } & \multicolumn{5}{|c|}{ Degree of association } \\
\hline & Topic related clusters & $N$ & in $\%$ & $\begin{array}{l}\text { The ideal } \\
\text { company }\end{array}$ & $\begin{array}{c}\text { Employee } \\
\text { culture }\end{array}$ & $\begin{array}{c}\text { Myself as } \\
\text { a } \\
\text { manager }\end{array}$ & $\begin{array}{l}\text { Leader- } \\
\text { ship } \\
\text { culture } \\
\end{array}$ & $\begin{array}{c}\text { The } \\
\text { company } \\
\text { today }\end{array}$ \\
\hline \multirow{5}{*}{ 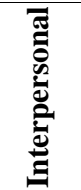 } & Self motivation through team spirit & 27 & $3.5 \%$ & .888 & .524 & .820 & .588 & .510 \\
\hline & Good relationsship with peers & 19 & $2.4 \%$ & .920 & .495 & .830 & .557 & .482 \\
\hline & Egocentricity, Silo-mentality & 26 & $3.3 \%$ & .303 & .596 & .374 & .498 & .590 \\
\hline & Impersonal togetherness / Blasphemy & 30 & $3.8 \%$ & .342 & .666 & .411 & .564 & .657 \\
\hline & Efficient and positive communication & 16 & $2.0 \%$ & .858 & .548 & .787 & .612 & .543 \\
\hline \multirow{6}{*}{ 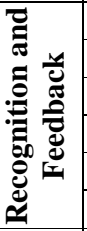 } & Responsility is not taken, no recognition & 15 & $1.9 \%$ & .316 & .685 & .377 & .581 & .683 \\
\hline & Performance orientation & 16 & $2.0 \%$ & .853 & .548 & .845 & .592 & .532 \\
\hline & Honest, critical feedback & 15 & $1.9 \%$ & .920 & .430 & .806 & .489 & .424 \\
\hline & Error prevention & 23 & $2.9 \%$ & .387 & .708 & .450 & .614 & .701 \\
\hline & Organizational Silence & 15 & $1.9 \%$ & .325 & .703 & .382 & .601 & .704 \\
\hline & Open error culture & 21 & $2.7 \%$ & .852 & .516 & .867 & .551 & .498 \\
\hline \multirow{4}{*}{ 冚 } & Employee development \& growth & 29 & $3.7 \%$ & .850 & .539 & .808 & .589 & .531 \\
\hline & Intrinsic passion for the job & 27 & $3.5 \%$ & .866 & .504 & .728 & .594 & .510 \\
\hline & Work-to-rule & 28 & $3.6 \%$ & .359 & .595 & .442 & .499 & .579 \\
\hline & Stay in the comfort zone & 18 & $2.3 \%$ & .340 & .785 & .395 & .672 & .783 \\
\hline \multirow{8}{*}{ 言 } & Autocratic Leadership & 15 & $1.9 \%$ & .364 & .602 & .423 & .525 & .603 \\
\hline & Cooperative Leadership & 19 & $2.4 \%$ & .895 & .515 & .786 & .590 & .508 \\
\hline & Clearly defined strategy and goals & 34 & $4.3 \%$ & .891 & .472 & .784 & .535 & .470 \\
\hline & Controlling supervisors & 14 & $1.8 \%$ & .467 & .814 & .471 & .811 & .862 \\
\hline & Unclear instructions, missing strategy & 30 & $3.8 \%$ & .310 & .640 & .384 & .533 & .630 \\
\hline & Clear \& distributed responsibilities & 20 & $2.6 \%$ & .883 & .506 & .829 & .556 & .495 \\
\hline & Involement is missing & 21 & $2.7 \%$ & .368 & .658 & .419 & .580 & .664 \\
\hline & Inclusion and involvement & 15 & $1.9 \%$ & .849 & .522 & .799 & .589 & .503 \\
\hline \multirow{12}{*}{ 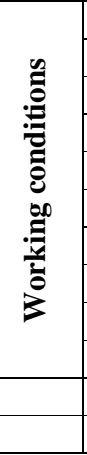 } & Exhaustion, overtime and demotivation & 26 & $3.3 \%$ & .357 & .681 & .422 & .584 & .675 \\
\hline & Wasteful processes & 31 & $4.0 \%$ & .327 & .668 & .396 & .564 & .661 \\
\hline & Agile working attitude / open-mindedness & 23 & $2.9 \%$ & .848 & .540 & .811 & .589 & .532 \\
\hline & Efficient working conditions & 32 & $4.1 \%$ & .879 & .509 & .754 & .588 & .511 \\
\hline & Sluggishness in change & 19 & $2.4 \%$ & .318 & .712 & .379 & .603 & .709 \\
\hline & Continuous optimization & 21 & $2.7 \%$ & .889 & .461 & .858 & .504 & .447 \\
\hline & Healthy working conditions & 15 & $1.9 \%$ & .754 & .588 & .832 & .593 & .562 \\
\hline & Innovative work environment & 13 & $1.7 \%$ & .853 & .547 & .781 & .611 & .544 \\
\hline & Salary and security & 19 & $2.4 \%$ & .745 & .651 & .767 & .677 & .635 \\
\hline & Pure profit orientation & 19 & $2.4 \%$ & .429 & .695 & .474 & .631 & .702 \\
\hline & (Unassigned) & 71 & $9.1 \%$ & .713 & .656 & .745 & .669 & .641 \\
\hline & Total & 782 & & & & & & \\
\hline
\end{tabular}

Source: Compiled by the authors

For this research, the clusters within recognition and feedback are relevant as they influence the leader's selfperception. The first hypothesis we developed from the literature review is that error prevention supports organizational silence in combination with a performance orientation. Firstly, we need to examine what kind of corporate culture dealing with errors is predominant in the underlying research subject. We would expect either a high degree of association of the "employee culture" as well as "the company today" with the location of the cluster open error culture (standing for error management) or error prevention. Error prevention shows an association degree of about $71 \%$ with the element employee culture. Likewise, organizational silence relates (to $70 \%$ ) with the employee culture. Besides, their spatial location is overlapping, which may indicate a thematic coherence of the two clusters. In contrast, an open error culture (error management) is associated with an ideal company (85\%) but is neither brought into context with the employee culture nor organizational silence. It supports hypothesis one with regards to error prevention and OS. On the other hand, performance orientation is only associated with a degree of $55 \%$, so the influence is undifferentiated. Looking like the perceived ideal company of the interviewees, it becomes evident that this element relates solely to a small degree with error prevention (39\%) and organizational silence (33\%), whilst performance orientation is positively associated in the context of an ideal company (85\%). We can conclude for hypothesis one that there is a linkage between error prevention and organizational silence. For performance orientation, the impact 
cannot be concluded but neither can the causal coherence be discarded. We highlight that in the underlying research case, performance orientation is associated with an ideal organization, whilst error prevention and organizational silence are strongly seen as negative aspects of a company.

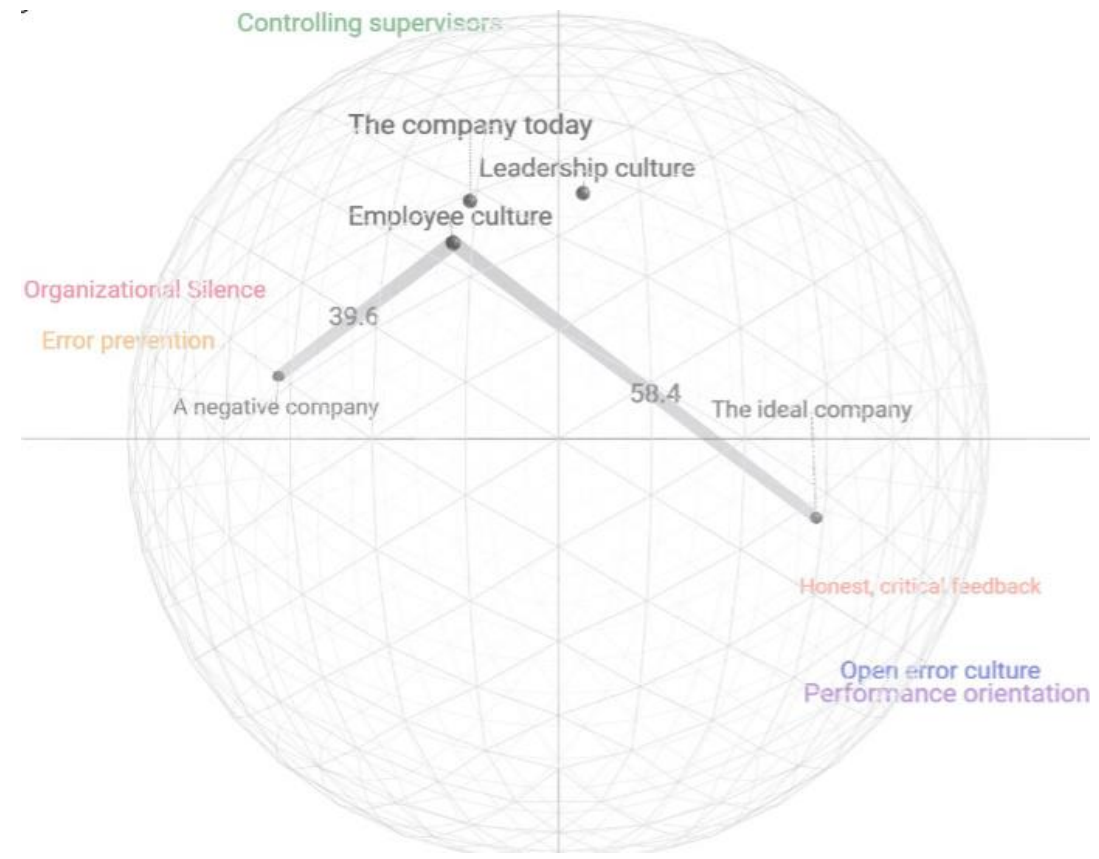

Figure 2. Relation of Error Management on Organizational Silence

Source: Compiled by the authors

Another subject that we identified in our study related to OS and error prevention is "controlling supervisors". It relates to $81 \%$ with the employee culture and leadership culture, which may indicate a linkage to organizational silence. As we cannot conclude from one case to a general causality, we suggest that further research on the causal connection of control by supervisors and organizational silence is conducted. As a second hypothesis, we postulated that the absence of feedback in combination with error prevention leads to a wrong self-perception or over-estimation in leadership. For the underlying research case, the findings from the literature review are supported as the element "myself as a manager" which the people in leadership positions only evaluated is situated closely to "The ideal company" (81\%) while the "Leadership culture" (which reflects the rating of the employees and leaders) is not associated with the ideal (48\%).

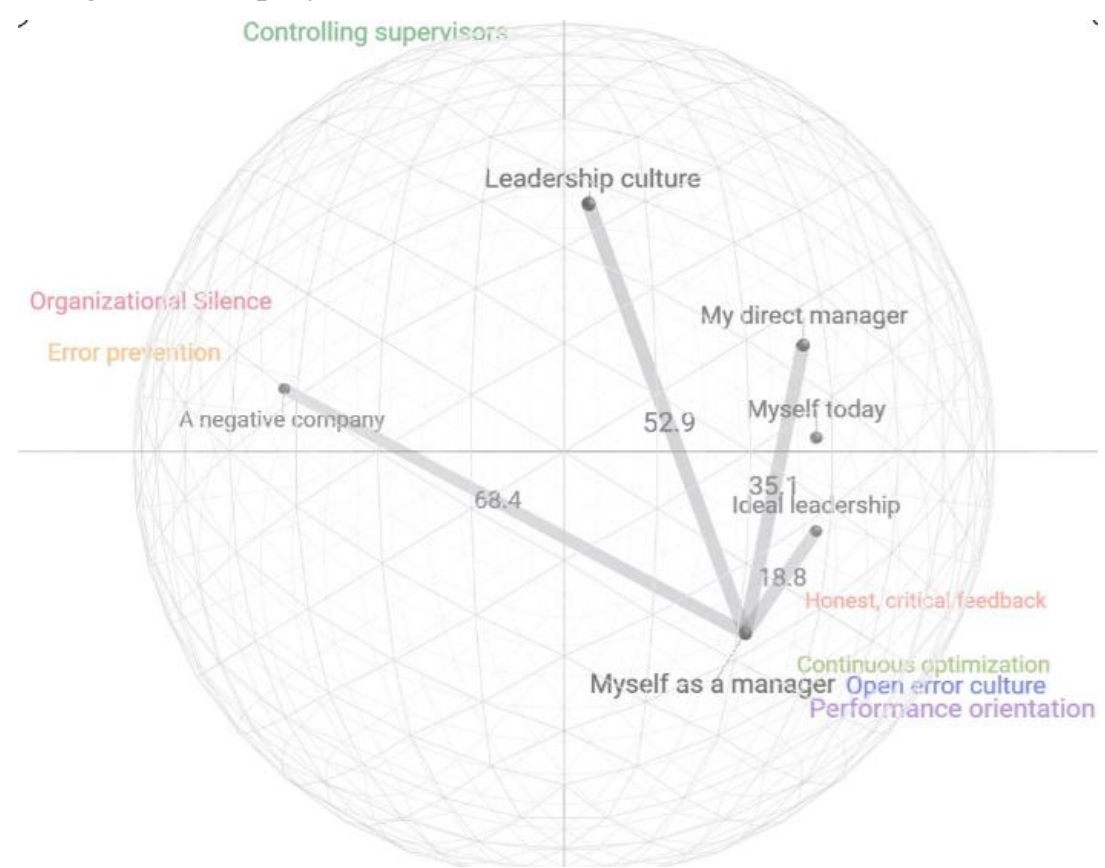

Figure 3. Devaluation of Leadership Culture in Contrast to the Direct Manager and the Self-Perception of Managers Source: Compiled by the authors 
In a corporate culture in which honest and critical feedback is implemented alongside an open error culture, we would expect the element "myself as a manager" assessed similar or slightly more favorable according to the findings by Atwater et al. (1998) that humans generally tend to perceive themselves positively and overestimate their competences (Atwater et al., 1998; Silvia and Duval, 2001). In the underlying case, managers perceive themselves as open for errors (87\%), to give honest and critical feedback (81\%) and foster performance $(85 \%)$. On the contrary, the leadership culture is closest to controlling supervisors ( $81 \%)$, whereas the three before mentioned elements rank below 60\%. Interestingly, employees' rate "my direct manager" persistently closer to the ideal (75\%) than the entire leadership culture. We expected that the aggregation of all "my direct manager" ratings would result in at least a very similar assessment as "our leadership culture," but our findings are contrary to that (see figure 3). It supports though the thesis that OS fosters overestimation in leadership, like Atwater et al. (1995) postulated. Employees devaluate the overall leadership culture but do not give critical feedback about their direct manager, resulting in a higher self-reflection of leaders in return. Our third hypothesis predicates that overestimating leadership supported by a culture where responsibility is not taken will result in the devaluation of the corporate culture. The following figure indicates the evidence we generated from our database:

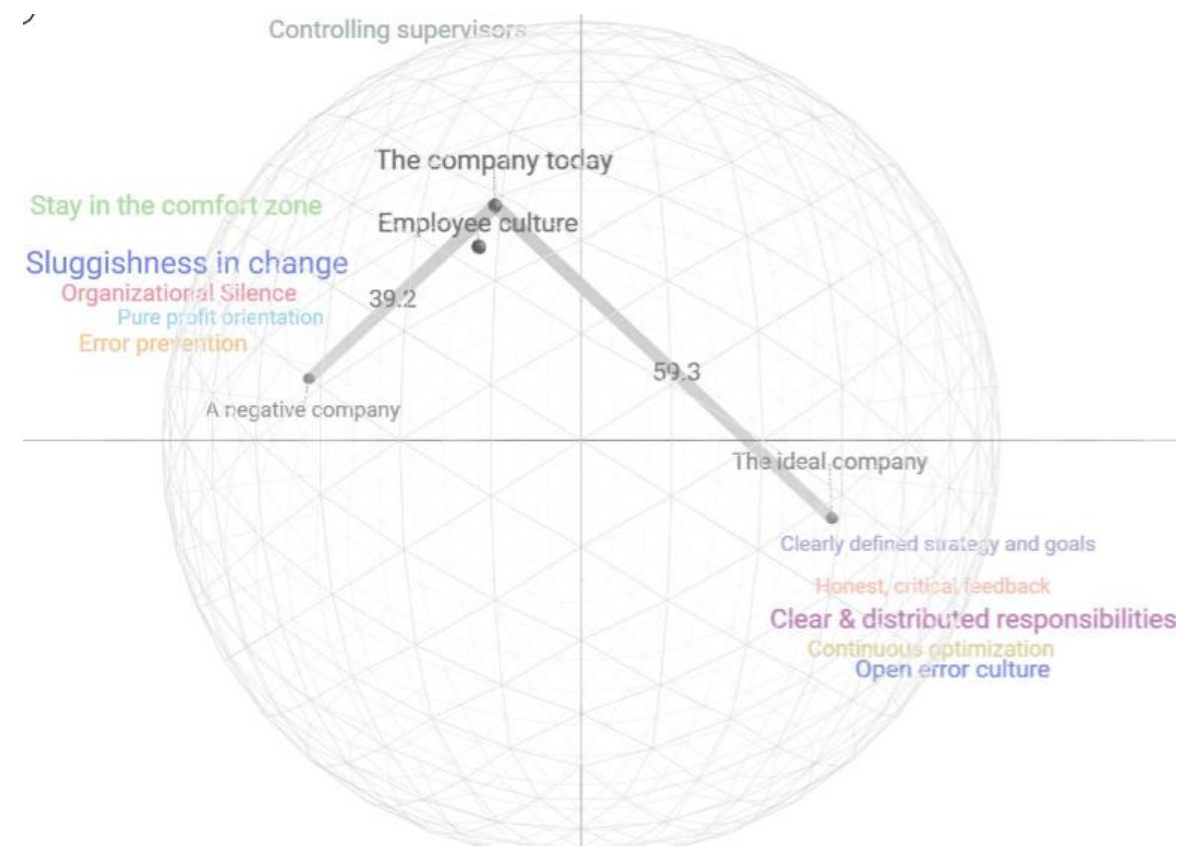

Figure 4. Devaluation of the Corporate Culture

Source: Compiled by the authors

The element "The company" today has the strongest relation with clusters that are also strongly associated with the participants perception of a negative company. Further, the locations of "The company today" same as the "Employee culture" are closer to an opposing company than the sematic corridor of "The ideal company". Stay in the comfort zone and Sluggishness in change are closely related to the unwillingness to take responsibility. Organizational silence and error prevention are clusters that also represent negative corporate cultures. Besides, the organization under review has a strong orientation towards profit which is perceived negatively by the interviewees. In our literature review, the topic of missing appreciation was touched in error management as while also in it is an element within the organizational silence. The literature had no clear proposition on the outcome in case of combining the two topics above. The data of this research study indicates that missing appreciation paired with error prevention and supported by a lack of involvement results in a culture in which employees do not take on responsibility. The following figure visualized this relation between the elements and construct clusters. 


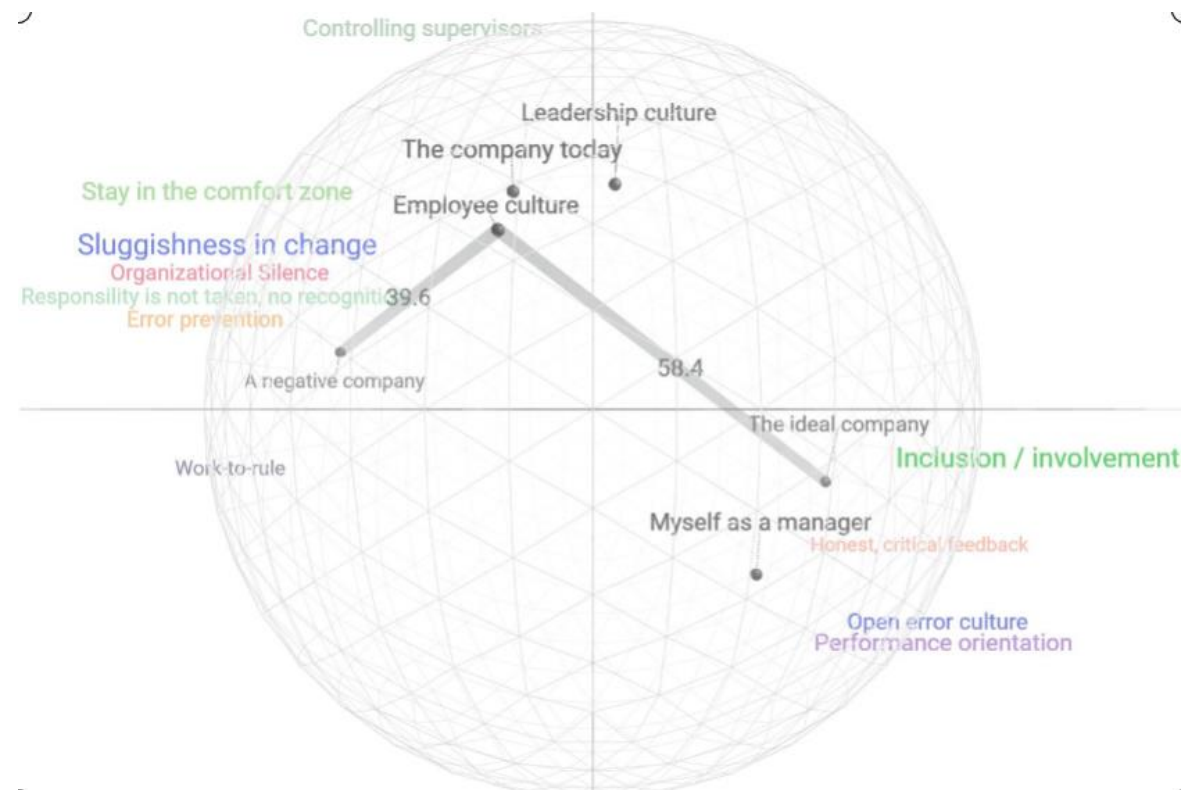

Figure 5. Devaluation of the Employee Culture with Regards to Proactivity

Source: Compiled by the authors

The employee culture is situated close to missing recognition and the absence of responsibility (69\%). However, it is not the strongest association of the investigated clusters. Still, it can be withdrawn from the data set that inclusion and involvement are not associated with the employee culture (52\%). Among the closest clusters, we find controlling supervisors $(81 \%)$, which additionally represents a culture that supports the prevention of errors. Moreover, stay in the comfort zone (79\%) and sluggishness in change (71\%) are closely connected. It supports the postulate that missing appreciation, error prevention / controlling supervisors and the absence of inclusion and involvement result in a culture in which employees do not take on responsibility. Instead, employees rather stay in their comfort zone. In other words, if employees are not appreciated by their supervisor and open communication about errors is not practiced, employees tend to avoid making autonomous decisions regarding their tasks. Thus, a leadership culture that does not include employees in decision-making processes will support this unwanted result of employees' avoidance of responsibility. The repertory grid study can only be the first test of plausibility on the literature review findings. Nevertheless, it supported us that error prevention and organizational silence are connected to the self-evaluation of leaders.

\section{Conclusion}

Summarized the introduced and applied research and hypothesis model could partially be verified for the research object of this study. Our research points out that an organization's error culture influences several areas that are critical to corporate culture. Also, our study indicates that an error prevention strategy can lead to the incorporation of employee silence, thus, to organizational silence. Furthermore, in return, we found that OS induces a falsified self-perception in leadership as there is little reason for managers to reflect on their habits. Besides, an error prevention strategy is likely to favor a habit where managers and employees try to avoid responsibility. Risk minimization is the prime objective, so not being responsible collateralizes negatives consequences for one work. In a culture of missing appreciation and a lack of involvement, avoidance of responsibility might be positively reinforced. The basis for our research was a literature review on selfperception in leadership, error management and organizational silence. We tried to point out the possible interrelationship of these three topics but were limited to a single research object with a comprehensive data basis. We advocate that further research on error management in corporate culture, mostly organizational silence, is conducted. Our study leads to the conclusion that error management has a considerable impact on the overall corporate culture. Particularly the mutual influences of error management with organizational silence and lack of responsibility are currently not stressed in the scientific literature.

Author Contributions. Conceptualization, Laura Kussin, Henning Bundtzen; data curation, Henning Bundtzen; formal analysis, Henning Bundtzen; investigation, Laura Kussin, Henning Bundtzen; methodology, Henning Bundtzen; software, Henning Bundtzen; supervision, Dr habil. Szilárd Berke; visualization, Henning Bundtzen; writing - original draft, Laura Kussin, Henning Bundtzen; writing - review \& editing, Laura Kussin, Hernning Bundtzen.

Funding. There is no funding for this research. 


\section{References}

1. Aarons, G., Ehrhart, M., Farahnak, L., Sklar, M., \& Horowitz, J. (2015). Discrepancies in Leader and Follower Ratings of Transformational Leadership: Relationship with Organizational Culture in Mental Health. Administration and Policy in Mental Health, 44(4), 480-491. https://doi.org/10.1007/s10488-015-0672-7.

2. Arkin, R.M., \& Shepperd, J.A. (1989). Self-Presentation Styles in Organizations. In R. A. Giacalone \& P. Rosenfeld (Eds.), Impression Management in the Organization (pp. 125-139). London: Taylor \& Francis Group. Available at: https://psycnet.apa.org/record/1990-97636-008.

3. Ashford, S. J. (1989). Self-assessments in organizations: A literature Review and integrative model. In L. L. Cummings \& B. M. Staw (Eds.). Research in organizational behavior (Vol. 11, pp. 133-174). Greenwich, CT: JAI Press.

4. Atwater, L., Ostroff, C., Yammarino, F., \& Fleenor, J. (1998). Self-other agreement: Does it really matter? Personel Psychology, 577-595. https://doi.org/10.1111/j.1744-6570.1998.tb00252.x.

5. Atwater, L., Roush, P., \& Fischthal, A. (1995). The Influence of Upward Feedback on Self- and Follower Ratings of Leadership. Personnel Psychology, 35-59. https://doi.org/10.1111/j.1744-6570.1995.tb01745.x.

6. Atwater, L., Waldman, D., Atwater, D., \& Cartier, P. (2000). An upward feedback field experiment: Supervisors' synicism, reaction and commitment to subordinates. Personnel Psychology, 53, 275-297. https://doi.org/10.1111/j.1744-6570.2000.tb00202.x.

7. Atwater, L., \& Yammarino, F. (1992). Does self-other agreement on leadership perceptions moderate the validity of leadership and performance predictions? Personnel Psychology, 45(1), 141-164. https://doi.org/10.1111/j.1744-6570.1992.tb00848.x.

8. Bourne, D., \& Jankowicz, D.A. (2018). The Repertory Grid Technique. In M. Ciesielska \& D. Jemielniak (Eds.). Qualitative Methodologies in Organization Studies (Vol. 6, pp. 127-149). Cham: Springer International Publishing. https://doi.org/10.1007/978-3-319-65442-3 6.

9. Bruce, J.A., Sosik, J.J., Jung, Dong, I., \& Berson, Y. (2003). Leadership Models, Methods, and Applications. In W. Borman, D. Ilgen, \& Klimoski, Richard, J. (Eds.). Handbook of psychology: v. 12. The Handbook of Organizational Culture and Climate: Industrial and organizational psychology (12th ed., 277-308). California: SAGE Publications. https://doi.org/10.1002/0471264385.wei1212.

10.Burell, G., \& Morgan, G. (1979). Sociological paradigms and organisational analysis: Elements of the sociology of corporate life. New York: Routledge. Available at: https://www.routledge.com/SociologicalParadigms-and-Organisational-Analysis-Elements-of-the-Sociology/Burrell-Morgan/p/book/9781857421149.

11.Cassell, C., Close, P., Duberley, J., \& Johnson, P. (2000). Surfacing embedded assumptions: Using repertory grid methodology to facilitate organizational change. European Journal of Work and Organizational Psychology, 9(4), 561-573. https://doi.org/10.1080/13594320050203139.

12.Dweck, C. S. (1986). Motivational processes affecting learning. American Psychologist, 41, 1040-1048. https://doi.org/10.1037/0003-066x.41.10.1040.

13.Easterby-Smith, M., Thorpe, R., \& Holman, D. (1996). Using repertory grids in management. Journal of European Industrial Training, 20(3), 3-30. https://doi.org/10.1108/03090599610114138.

14.Feixas, G., Geldschläger, H., \& Neimeyer, R. A. (2002). Content analysis of personal constructs. Journal of Constructivist Psychology, 15(1), 1-19. https://doi.org/10.1080/107205302753305692.

15.Fischer, S., Frese, M., Mertins, J.C., \& Hardt-Gawron, J.V. (2018). The Role of Error Management Culture for Firm and Individual Innovativeness. Applied Psychology, 67(3), 428-453. https://doi.org/10.1111/apps.12129.

16.Flynn, C.B., Smither, J.W., \& Walker, A.G. (2016). Exploring the Relationship Between Leaders' Core Self-Evaluations and Subordinates' Perceptions of Servant Leadership. Journal of Leadership \& Organizational Studies, 23(3), 260-271. https://doi.org/10.1177/1548051815621257.

17.Fransella, F. (Ed.) (2004). International handbook of personal construct psychology. Chichester u.a: Wiley. https://doi.org/10.1002/0470013370.

18.Fransella, F., Bell, R., \& Bannister, D. (2004). A manual for repertory grid technique (2 ed.). Chichester: Wiley. 12-52. Available at: http://www.loc.gov/catdir/bios/wiley046/2003014732.html.

19.Frederick, O. (2019). Employees' Expectation and Organizational Silence. Annals of Dunarea De Jos University of Galati. Fascicle I [The Annals of the Lower Danube University of Galati]. Economics and Applied Informatics, 25(1), 93-102. https://doi.org/10.35219/eai1584040911.

20.Frese, M., \& Keith, N. (2015). Action errors, error management, and learning in organizations. Annual Review of Psychology, 66, 661-687. https://doi.org/10.1146/annurev-psych-010814-015205.

21.Fromm, M. (2004). Introduction to the Repertory Grid Interview. s.l.: Waxmann Verlag. Available at: https://content-select.com/portal/media/cover_image/54f81ebe-cda8-4bff-9aca-71e0b0dd2d03/500. 
22.Gao, L., Janssen, O., \& Shi, K. (2011). Leader trust and employee voice: The moderating role of empowering leader behaviors. The Leadership Quarterly, 22(4), 787-798. https://doi.org/10.1016/j.leaqua.2011.05.015.

23.Ghoshal, S., \& Moran, P. (1996). Bad for Practice: A Critique of the Transaction Cost Theory. The Academy of Management Review, 21, 13-47. https://doi.org/10.5465/amr.1996.9602161563.

24.Goffin, K. (2003). Repertory Grid Technique. In D. Partington (Ed.). Essential skills for management research (pp. 199-225). London: SAGE. https://doi.org/10.4135/9781848605305.n11.

25.Gong, Y., Wang, M., Huang, J.-C., \& Cheung, S.Y. (2017). Toward a Goal Orientation-Based Feedback-

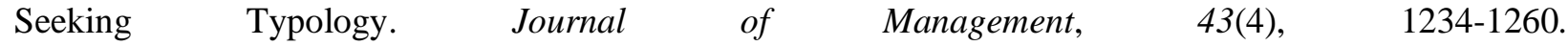
https://doi.org/10.1177/0149206314551797.

26.Gower, J. (1975, January). Generalized Procrustes analysis. Psychometrika 45(1), 3-24. http://dx.doi.org/10.1007/bf02291478.

27.Grice, J.W., \& Assad, K.K. (2009). Generalized Procrustes Analysis: A Tool for Exploring Aggregates and Persons. Academy of Management Review, 13(1), 93. https://doi.org/10.22329/amr.v13i1.2836.

28.Guenther, C., \& Alicke, M. (2010). Deconstructing the better-than-average effect. Journal of Personality and Social Psychology, 99(5), 755-770. https://doi.org/10.1037/a0020959.

29.Hauser, M., Jonas, K., \& Riemann, R. (2011). Measuring salient food attitudes and food-related values. An elaborated, conflicting and interdependent system. Appetite, 57(2), 329-338. https://doi.org/10.1016/j.appet.2011.05.322.

30.Hofmann, D.A., \& Frese, M. (2011). Errors, Error Taxonomies, Error Prevention and Error Management: Management: Laying the Groundwork for Discussing Errors in Organizations. In D. Hofmann \& M. Frese (Eds.). Errors in Organizations (pp. 1-43). New York: Routledge. Available at: https://www.taylorfrancis.com/chapters/errors-error-taxonomies-error-prevention-error-management-layinggroundwork-discussing-errors-organizations-david-hofmann-michael-frese/e/10.4324/9780203817827-8.

31.Kane-Urrabazo, C. (2006). Management's role in shaping organizational culture. Journal of Nursing Management, 14, 188-194. https://doi.org/10.1111/j.1365-2934.2006.00590.x.

32.Keith, N., \& Frese, M. (2005). Self-regulation in error management training: Emotion control and metacognition as mediators of performance effects. The Journal of Applied Psychology, 90(4), 677-691. https://doi.org/10.1037/0021-9010.90.4.677.

33.Keith, N., \& Frese, M. (2008). Effectiveness of error management training: A meta-analysis. The Journal of Applied Psychology, 93(1), 59-69. https://doi.org/10.1037/0021-9010.93.1.59.

34.Kelly, G. (2002). The Psychology of Personal Constructs: Routledge. 32-124. https://doi.org/10.4324/9780203405970.

35.Kelly, G.A. (1955). The Psychology of Personal Constructs. Norton, New York. 12-76. Available at: https://psycnet.apa.org/record/2006-10238-008.

36.Kelly, G.A. (1991). The psychology of personal constructs: Volume two: Clinical diagnosis and psychotherapy. London: Routledge; Tylor \& Francis Group. 23-89. Available at: https://www.routledge.com/The-Psychology-of-Personal-Constructs-Volume-Two-Clinical-Diagnosisand/Kelly/p/book/9780415037983.

37.Lohaus, A. (1983). Möglichkeiten individuumzentrierter Datenerhebung. [Possibilities of individualcentered data collection]. Zugl.: Münster (Westfalen), Univ., Diss. Arbeiten zur sozialwissenschaftlichen Psychologie: $\quad$ Vol. $12 . \quad$ Münster: Aschendorff. Available at: https://www.zvab.com/9783402042922/M\%C3\%B6glichkeiten-individuumzentrierter-DatenerhebungArnold-Lohaus-3402042924/plp.

38.London, M., \& Smither, J. (2002). Feedback orientation, feedback culture, and the longitudinal performance management process. Human Resource Management Review, 12(1), 81-100. https://doi.org/10.1016/S1053-4822(01)00043-2.

39.Mak, A.H.N., Lumbers, M., Eves, A., \& Chang, R.C.Y. (2013). An application of the repertory grid method and generalised Procrustes analysis to investigate the motivational factors of tourist food consumption. $\begin{array}{lllll}\text { International Journal of Hospitality } & \text { Management, } & 35, & 327-338 .\end{array}$ https://doi.org/10.1016/j.ijhm.2013.07.007.

40.Morrison, E.W., \& Milliken, F. (2000). Organizational Silence: A Barrier to Change and Development in a Pluralistic World. The Academy of Management Review, 706-725. https://doi.org/10.5465/amr.2000.3707697.

41.Morrison, E.W., See, K.E., \& Pan, C. (2015). An Approach-Inhibition Model of Employee Silence: The Joint Effects of Personal Sense of Power and Target Openness. Personnel Psychology, 3, 547-580. https://doi.org/10.1111/peps.12087. 
42.Pinder, C.C., \& Harlos, K.P. (2001). Employee Silence: Quiescence and Acquiescence as Responses to Perceived Injustice. Research in Personnel and Human Resources Management, 331-369. https://doi.org/10.1016/S0742-7301(01)20007-3.

43.Prümper, J., \& Zapf, Dieter, Brodeck, Fleix C., Frese, Michael. (2007). Some surprising differences between novice and expert errors in computerized office work. Behaviour \& Information Technology, 11, 319-328. https://doi.org/10.1080/01449299208924353.

44.Ramani, S., Könings, K.D., Ginsburg, S., \& Van Der Vleuten, C.P.M. (2018). Twelve tips to promote a feedback culture with a growth mind-set: Swinging the feedback pendulum from recipes to relationships. Medical Teacher, 41(6), 625-631. https://doi.org/10.1080/0142159X.2018.1432850.

45.Riemann, R. (1991). Repertory Grid Technik: Handanweisung, Auswertungsprogramm, Materialien. Göttingen: Hogrefe. Available at: https://pub.uni-bielefeld.de/record/1894361.

46.Robertson, A. (2004). Making Sense of the 'Group Mind'. In F. Fransella (Ed.). International handbook of personal construct psychology (pp. 339-348). Chichester u.a: Wiley. https://doi.org/10.1002/0470013370.ch34.

47.Scheer, J.W., \& Catina, A. (Eds.) (1993). Einführung in die Repertory Grid-Technik. [Introduction to Repertory Grid Technique] Bd. 2. Klinische Forschung und Praxis (1. Aufl.). Bern, Göttingen, Toronto, Seattle: Huber. Available at: https://www.zvab.com/9783456820750/Einf\%C3\%BChrung-RepertoryGrid-Technik-Klinische-Forschung-3456820755/plp.

48.Schein, E.H., \& Schein, P. (2010). Organizational Culture and Leadership (5th ed.): Wiley. Available at: https://www.wiley.com/en-us/Organizational+Culture+and+Leadership\%2C+5th+Edition-p-9781119212041.

49.Senior, B., \& Swailes, S. (2004). The dimensions of management team performance: a repertory grid study. International Journal of Productivity and Performance Management, 53(4), 317-333. https://doi.org/10.1108/17410400410533908.

50.Silvia, P., \& Duval, T.S. (2001). Objective Self-Awareness Theory: Recent Progress and Enduring $\begin{array}{llll}\text { Problems. } \quad \text { Personality } & \text { Social } & \text { Psychology, } & 30-241 .\end{array}$ https://doi.org/10.1207/S15327957PSPR0503_4.

51.Sputtek, R. (2012). Opening the Black Box. Wiesbaden: Gabler Verlag. 14-68. https://doi.org/10.1007/9783-8349-3925-8.

52.Sutcliffe, K.M. (2011). Organizational Environments and Organizational Information Processing. In F. M. Jablin \& L.L. Putnam (Eds.). The New Handbook of Organizational Communication (pp. 198-230). Thousand Oaks: Sage Publication. https://dx.doi.org/10.4135/9781412986243.

53.Tangirala, S., \& Ramanujam, R. (2012). Ask and you shall hear (but not always): Examining the relationship between manager consultation and employee voice. Personnel Psychology, 65, 251-282. https://doi.org/10.1111/j.1744-6570.2012.01248.x.

54.Tekleab, A.G., Sims, H.P., Yun, S., Tesluk, P.E., \& Cox, J. (2008). Are We on the Same Page? Effects of Self-Awareness of Empowering and Transformational Leadership. Journal of Leadership \& Organizational Studies, 3, 185-201. https://doi.org/10.1177/1071791907311069.

55.Tomic, O., Berget, I., \& Næs, T. (2015). A comparison of generalised procrustes analysis and multiple factor analysis for projective mapping data. Food Quality and Preference, 43, 34-46. https://doi.org/10.1016/j.foodqual.2015.02.004.

56.Van Dyne, L., Ang, S., \& Botero, I. (2003). Conceptualizing Employee Silence and Employee Voice as Multidimensional Constructs Journal of Management Studies, 40(6), 1360-1391. https://doi.org/10.1111/1467-6486.00384.

57.Walker, A.G., \& Smither, J.W. (1999). A five-year study of upward feedback: What managers do with their results matters. Personnel Psychology, 52, 343-423. https://doi.org/10.1111/j.1744-6570.1999.tb00166.x.

58.Whitton, S.W., Larson, J.J., \& Hauser, S.T. (2008). Depressive symptoms and bias in perceived social competence among young adults. Journal of Clinical Psychology, 64(7), 791-805. https://doi.org/10.1002/jclp.20488.

59.Wright, R.P., \& Lam, S.S.K. (2002). Comparing apples with apples: the importance of element wording in grid applications. Journal of Constructivist Psychology, 15(2), 109-119. https://doi.org/10.1080/10720530252808692.

60.Zhou, J., \& Georg, J.M. (2001). When job dissatisfaction leads to creativity: encouraging the expression of voice. Journal of Applied Psychology, 44, 682-696. https://doi.org/10.2307/3069410. 